\title{
Background Note for the Section on Financing and Governance [Overview Paper]
}

\author{
Liviu Matei
}

The original ambition of the section on Financing and Governance of the 2nd Bologna Researchers' Conference had been to review key aspects in this area along the Bologna action lines. This would have meant a discussion about funding of the Social Dimension in the European Area of Higher Education, of Student Mobility, Attractiveness of the European Higher Education Area in the World, Lifelong Learning, Promotion of European Cooperation in Quality Assurance, of any or all the other action lines. This was not possible in the end at this Conference and it might not be possible at all. It would have been a discussion, in a way, about Funding Bologna, which is a fascinating theme of reflection. The papers in this section are subsumed eventually, directly or only indirectly, to the seemingly more mundane theme of Financing and Governance in the European Higher Education Area. This, in fact, is not an uninteresting or simple theme either.

The European space for dialogue in higher education made possible by the Bologna Process has helped bring about new policies, concepts, tools, or practices in many areas of higher education, from the structure of degrees to quality assurance, and from student mobility to access and equity. There has been very little, or almost no such innovation brought about by the Bologna Process in the area of funding. Still, there are important elements of specificity, even originality, in Europe in the area of funding and governance; characteristics that have emerged because of or along with the advancement of the Bologna Process.

A defining aspect to consider when discussing characteristics of funding and governance in the European Higher Education Area has to do with the very fact that funding has not been a formal concern, let alone an objective, of the Bologna Process. Although the Process could be seen as a "project" (almost in a genuine, narrow managerial perspective, despite its large, continental scope of ambitions) it has not comprised planning about funding, or about funding instruments, as we would expect in any stark "project" (Matei 2012). There has never been a Bologna funding action line, a Bologna-wide funding policy, not even a Bologna-wide discussion about funding policies, let alone a Bologna budget. In a way, funding is,

\footnotetext{
L. Matei $(\bowtie)$

Central European University, Budapest, Hungary

e-mail: mateil@ceu.edu

(C) The Author(s) 2015

A. Curaj et al. (eds.), The European Higher Education Area,

DOI 10.1007/978-3-319-20877-0_10
} 
surprisingly, an "absent theme" of Bologna. How could it then generate any developments, let alone innovative ones, in this field?

A second defining aspect is that key European characteristics (and some innovative developments) in the field of funding are indeed related to Bologna, however they have been started or steered from outside Bologna. An immediate example is the funding of student mobility under the Erasmus programs, a major innovative European initiative. The Erasmus programs are not Bologna programs, although they share the Bologna philosophy and were meant to support achieving important Bologna objectives.

In the European context, a discussion about financing and governance of higher education during the last 15-20 years will unavoidably identify significant elements and characteristics that are specifically, even uniquely European, whether they are linked to Bologna or not. This is not to say that there are no challenges, tools, policies or practices in these areas that are not similar to or common with those in other parts of the world.

In a simplified presentation, it could be stated that such elements of specificity are linked primarily to two sources. The first one is the traditional role of the state in funding and governance of higher education. For example, public funding remains the dominant source of funding in Europe, representing between 50 and $90 \%$ of the income of universities (Estermann et al. 2013). The second one is the existence of large projects of a transnational nature ("European" projects) in higher education: the project of the European Higher Education Area itself, envisioned to be built through the Bologna Process and involving basically all countries of the continent; and the project of the European Research Area, which is a major initiative of the European Union in the area of research, including university research, with significant implications on higher education more broadly and extending beyond the borders of the EU. This is a very particular and interesting political, policy, and also operational context. Although this way of presentation is oversimplified, it allows nevertheless pointing to key dynamics, challenges and also contradictions in the field of governance and funding. The papers in this section will focus on some of these European challenges, dynamics, and contradictions.

A specific European characteristic is the tension between the dominant national nature of the funding and decision-making in higher education more generally, and the existence of transnational, European commitments in higher education. Such commitments, as expressed in the consecutive Bologna ministerial communiqués, for example, could be considered as joint European objectives. The question could be asked how are these European objectives funded? Or how should they be funded? Since there is no Bologna budget or budgeting, whose job is it to adopt and implement funding policies with regard to European-wide objectives? Is it the job of the national governments? Perhaps only for the parts that concern directly their own territories and citizens? This answer would be complicated and contradictory, considering the cross-border nature of many Bologna activities. Or perhaps it is the job of the European Union, which fortunately has a budget? Only that Bologna and the EU, or the EU processes in higher education more precisely, are not one and the same in terms of membership, legal foundations, or institutional functioning. Here 
again, the question could be asked who should think about and decide on the funding of any and all of the dimensions mentioned in the introduction to this note and defining the European Higher Education Area? Clearly, there is no Bologna formal preoccupation, let alone institutional mechanism in place, to back the continental ambitions and objectives of the Process with correspondingly European-wide funding policies and mechanisms. The funding landscape is fragmented, with many cross-national differences. National funding policies may or may not consider Bologna objectives or commitments.

In fact, one could state that dynamics and developments at the institutional and national level in the area of funding are most often not related to Bologna. To date, however, there is no comprehensive study on how funding policies at the system level considers Bologna commitments or action lines. It is only rare that studies exist about, at least, how specific dimensions of Bologna are funded (see for example ESU (2013) for such an attempt).

The five papers in this section consider these and other characteristics of the European context with regard to funding and governance. They combine qualitative and quantitative methods, focusing on funding of particular areas, such as research and internationalization, or discuss funding patterns in an ambitious, comprehensive perspective. They identify trends and try to formulate policy lessons for this area, taking a comparative European and global perspective. One paper provides a mirroring perspective from another part of the world regarding the potential relevance of regional approaches to addressing challenges in university governance.

The chapter by Bennetot-Pruvot and Estermann is based on findings of the DEFINE project led by the European University Association. An applied policy study, DEFINE is one of the most important studies in recent times regarding the public funding of universities in Europe. In this chapter, the authors present a synopsis of the current patterns of public funding in European higher education. This is possibly the most complete and informative presentation of the patterns of public funding in Europe currently available. The funding patterns are analysed as responses coming from the public authorities to current societal and economic developments. The chapter looks in particular at funding modalities meant to increase efficiency in universities. Particular attention is given to two modalities, performance-based funding and the so-called "excellence initiative", looking at how they are used in different European countries and drawing lessons about what factors make them efficient or less efficient instruments, at positive outcomes and unintended consequences. This is altogether a remarkable study. What is even more directly connected with the overarching theme of this section is that the comprehensive review of current funding patterns in Europe reveals no reference to Bologna or to the European Higher Education Area. It appears that funding stakeholders, public authorities in particular, see no need (or value) in referring to Bologna when discussing or deciding on these matters. In other words, it looks as if key developments in the area of funding in Europe are disconnected from the Bologna Process.

The chapter by Erno Keszei et al. provides a good illustration of the dilemmas associated with the relationship between national funding, needs and objectives, on 
one side, and European ambitions and funding possibilities, on the other. The study focuses specifically on university research funding. The authors take as a starting point the level of the research performance in the universities of Eastern Central European countries, which remains significantly lower, compared to their counterparts in Western Europe and in other advanced higher education systems. But they also point out that the level of university research funding in Eastern Central Europe is dismal in comparison, which to a large extent explains differences in performance. What is even more worrisome is that national public authorities in this region appear to expect that European sources fill the gap. The authors claim that this attitude is dangerous. They argue that unless sufficient national funding is mobilized to support research, in addition to the European funding, there will be severe consequences in the short and long run. Their analysis looks at the funding of research in Eastern Central Europe in a comparative European and global perspective. Moreover, this analysis is developed considering not only traditional arguments pertaining to the logic of competitiveness and economic development, but also cultural and moral arguments, as expressed in European and UN documents and initiatives.

In their chapter, Vlasceanu and Hancean use a quantitative approach to study the relationship between funding and research performance. In particular, they address the questions whether and also how the increase of research funding leads to higher productivity and to an increased impact measured by usual indicators (Hirsch and Egghe index scores). The results, based on a Romanian case study, appear to indicate that increased funding leads indeed to more research and more publications, but at least in this case not at all to an increased impact. Their conclusion is that the volume of funding alone is not a good predictor for the impact of research, and that effective research funding policies must include other elements and incentives as well.

The chapter by Matei, Iwinska, and Craciun is an exploratory inquiry into the study of internationalization of higher education from a funding perspective. The authors propose that significant new insight in this area could be gained by studying patterns of funding of internationalization. They propose a simple and flexible conceptual framework to make such a study possible, to identify patterns of funding of internationalization and understand how they work. The chapter provides a series of examples to illustrate this new approach at work, primarily based on European experiences in internationalization. The authors argue that the insight made possible by this new approach goes beyond the simply factual (like helping to identify new mechanisms or instruments of funding of internationalization, or even identify new types of internationalization activities). It helps to better conceptualize internationalization itself and refine the study of internationalization. The authors further argue that the examples put forward in this chapter in relation to the proposed new conceptual framework for the study of internationalization add to the mainstream literature on internationalization and open new avenues of research of the internationalization phenomenon. For example, it is argued that funding patterns help to understand what "European internationalism" is, and what makes it a particular model of internationalization. 
The chapter by Sauwakon Ratanawijitrasin completes the section on funding and governance with a perspective from South East Asia. The author reviews in a comprehensive presentation challenges and recent developments in the area of governance in the countries of the region. She argues that the European experience of regional integration could provide an important set of lessons and models for addressing such challenges in South East Asia, with a particular focus on governance. This chapter argues for the relevance of the European experience, of the Bologna Process, beyond the borders of our own continent.

Open Access This chapter is distributed under the terms of the Creative Commons Attribution Noncommercial License, which permits any noncommercial use, distribution, and reproduction in any medium, provided the original author(s) and source are credited.

\section{References}

Estermann, T., Bennetot-Pruvot, E., \& Clayes-Kulik, A.-L. (2013). Designing strategies for efficient funding of higher education in Europe. DEFINE interim report, European University Association.

ESU, The European Students' Union. (2013). The compendium on financing of higher education. Final report of the Financing the Students' Future Project, Brussels.

Matei, L. (2012). A policy gap: Financing in the European higher education area. In A. Curaj, P. Scott, L. Vlasceanu, \& L. Wilson (Eds.), European higher education at the crossroads: Between the Bologna process and national reforms (pp. 667-690). Springer, Berlin. 